\title{
Prostate Cancer Survival By Risk of Progression and Other Prognostic Factors in Mallorca, Spain
}

\section{Juan-José Montaño ( $\nabla$ juanjo.montano@uib.es )}

Universitat de les Illes Balears https://orcid.org/0000-0002-1116-1964

\section{Antoni Barceló}

Mallorca Cancer Registry. Balearic Islands Public Health Department

\section{Paula Franch}

Mallorca Cancer Registry. Balearic Islands Public Health Department

\section{Jaume Galceran}

Tarragona Cancer Registry. Cancer Epidemiology and Prevention Service. Hospital Universitari Sant Joan de Reus. Institut d'Investigació Sanitària Pere Virgili (IISPV)

\section{Alberto Ameijide}

Tarragona Cancer Registry. Cancer Epidemiology and Prevention Service. Hospital Universitari Sant Joan de Reus. Institut d'Investigació Sanitària Pere Virgili (IISPV)

\section{Jaime Pons}

Mallorca Cancer Registry. Balearic Islands Public Health Department. Balearic Islands Health Research Institute (IdISBa)

\section{Maria Ramos}

Mallorca Cancer Registry. Balearic Islands Public Health Department. Balearic Islands Health Research Istitute (IdISBa)

\section{Research}

Keywords: prostate neoplasm, survival, stage, multiple imputation.

Posted Date: September 3rd, 2021

DOI: https://doi.org/10.21203/rs.3.rs-826613/v1

License: (c) (i) This work is licensed under a Creative Commons Attribution 4.0 International License. Read Full License 
Category: Original paper

Title: Prostate cancer survival by risk of progression and other prognostic factors in Mallorca, Spain

Short title: Prostate cancer survival by risk of progression

Dr. Juan-José Montaño ${ }^{1}$, Dr. Antoni Barceló ${ }^{2}$ Paula Franch², Dr. Jaume Galceran³, Alberto Ameijide ${ }^{3}$ Dr. Jaime Pons ${ }^{4}$ and Dr. Maria Ramos ${ }^{4}$.

1. University of Balearic Islands. Balearic Islands Health Research Institute (IdISBa).

2. Mallorca Cancer Registry. Balearic Islands Public Health Department.

3. Tarragona Cancer Registry. Cancer Epidemiology and Prevention Service. Hospital Universitari Sant Joan de Reus. Institut d'Investigació Sanitària Pere Virgili (IISPV). Reus, Spain.

4. Mallorca Cancer Registry. Balearic Islands Public Health Department. Balearic Islands Health Research Institute (IdISBa).

Corresponding author: Dr. Juan-José Montaño

Address: Cra. De Valldemossa, Km. 7,5 - Faculty of Psychology - University of Balearic Islands - 07122 (Balearic Islands, Spain)

Phone: +34971172495 - Fax: +34971173190

Mail: juanjo.montano@uib.es

https://orcid.org/0000-0002-1116-1964 


\section{Prostate cancer survival by risk of progression and other prognostic factors in Mallorca, Spain}

\section{Abstract}

Objectives: 1) to find out the distribution of prostate cancer by risk of progression; 2) to determine the causespecific survival by risk of progression in prostate cancer; 3 ) to identify the factors associated with the risk of dying from this cancer.

Methods: Incident prostate cancer cases diagnosed between 2006 and 2011 were identified through the Mallorca Cancer Registry. Inclusion criteria: invasive cases with code C61.9 and any histology. Cases identified exclusively through death certificate were excluded. We collected: age; date and method of diagnosis; date of follow-up or death; T, N, M and stage according to the TNM $7^{\text {th }}$ edition; Gleason score; PSA (prostatespecific antigen); histology according to the ICD-O (International Classification of Diseases for Oncology) $3^{\text {rd }}$ edition $^{6}$; comorbidities and treatments. We calculated risk in 4 categories: low, medium, high and very high. End point of follow-up was 31 December 2014. Multiple imputation (MI) was performed to estimate cases with unknown risk of progression. Survival analysis was performed using the actuarial and Kaplan-Meier methods, as well as the Cox regression model.

Results: We identified 2921 cases. After MI, 9.5\% had low risk, 24.9\% medium risk, $42.7 \%$ high risk and $22.9 \%$ very high risk. Five years after diagnosis, survival after MI was $89 \%$ globally, that being $100 \%$ for low risk cases, $96 \%$ for medium risk, $93 \%$ for high risk and $69 \%$ for very high risk. Cases with histology other than adenocarcinoma, with high and, especially, very high risk of progression, as well as with systemic, mixed and observation/unspecified treatments have worse prognosis. Treatment showed a strong relationship with age and life expectancy.

Conclusions: Risk of progression and treatment were the main variables associated to survival in prostate cancer.

Keywords: prostate neoplasm, survival, stage, multiple imputation. 


\section{Introduction}

Prostate cancer is the most frequent cancer in men in the European Union and the second one in the world, with an estimated world age-standardized incidence rate (ASIRw) of 62.1 cases per 100,000 men for 2020 [1]. The Spanish Network of Cancer Registries (REDECAN) has estimated a world ASIRw of 67.7 (95\%Cl: 53.982.8) for 2020 [2]. Estimated age-standardized mortality rates are much lower: 10.2 for Europe and 7.5 for Spain for 2020 [1].

The EUROCARE-5 study estimated, for the 2000-2007 period, a 5-year relative survival rate (5RS) for prostate cancer of $83.4 \%(83.1-83.6)$ in Europe and of $84.7 \%$ (83.6-85.6) in Spain [3]. Striking rises in 5RS of prostate cancer have occurred in Spain [4] as well as in many other countries, as the CONCORD-2 study reported for the 1995-2009 period [5]. Both studies concluded that the information about stage only is not enough to explain the differences in survival observed among countries.

Stage is the main prognostic factor in most cancers. However, for prostate cancer, the International Union Against Cancer (UICC) proposed in its $7^{\text {th }}$ edition [6] a new classification based on prognostic groups, using not only the $\mathrm{T}, \mathrm{N}$ and $\mathrm{M}$ components of TNM but also the histopathological grade or Gleason score, and the PSA (prostate-specific antigen) value. There are many classifications to classify the risk of progression in men with localized prostate cancer with different number of categories: in 3 categories (low, medium and high) [7]; in 4 (low, medium, high and very high) [8]; in 5 (very low, low, medium low, medium high and high) [9]; and even in 7 (considering 5 localised categories, 1 for clinical lymph node involvement and 1 for disseminated metastases) [10]. Since stage in prostate cancer cannot be determined due to $\mathrm{N}$ and $\mathrm{M}$ being usually unknown, this new classification involving risk stratification helps to overcome the problem of stage as a only prognostic factor for prostate cancer. Studies about survival of patients with prostate cancer by stage or risk of progression are scarce. Other factors associated to survival in prostate cancer are age [3], comorbidity [11] and treatment [12].

The aims of this study were: 1) to find out the distribution of prostate cancer by risk in the patients of Mallorca diagnosed in the period 2006-2011. 2) to determine the cause-specific survival (CSS) by risk in prostate cancer 
patients of Mallorca diagnosed in the period 2006-2011; and 3) to identify the factors that explain and predict the likelihood of survival and the risk of dying from this type of cancer.

\section{Methods}

This was a population-based retrospective follow-up study of patients living in Mallorca diagnosed with invasive prostate cancer between 2006 and 2011. We included all invasive prostate cancers of any histology according to the ICD-O (International Classification of Diseases for Oncology) $3^{\text {rd }}$ edition (code C61.9) [6], identified through the Mallorca Cancer Registry. Cases exclusively identified through the death certificate only (DCO) and cases without follow-up were excluded.

The following variables were collected: age, date of diagnosis, basis of diagnosis, date of follow-up or death; $T, N, M$ and stage according to the TNM $7^{\text {th }}$ edition, Gleason score (differentiating the value 7 as $4+3$ or $3+4$ ); PSA, histology (according to the ICD-O $3^{\text {rd }}$ edition) [13], comorbidities and treatments (prostatectomy, radiotherapy, cryosurgery, hormonal therapy, chemotherapy, active surveillance, expectant attitude and unknown).

Age was categorized in the following groups: $15-54,55-64,65-74,75-84$ and 85 years old and over. Life expectancy greater than or less than 10 years was also calculated according to the adjusted life expectancy at birth in the Balearic Islands [14]. Each individual survival time was defined from data of diagnosis to date of last known vital status (death by any cause, date of loss of follow-up, or date of end of follow-up at $31^{\text {st }}$ December 2014). Vital status was categorized as: alive (0), dead by prostate cancer (1) and dead by other causes (2).

We grouped PSA in: $\leq 10 \mathrm{ng} / \mathrm{ml}, 11-20 \mathrm{ng} / \mathrm{ml}$, and $>20 \mathrm{ng} / \mathrm{ml}$. We calculated risk of progression using $\mathrm{T}, \mathrm{N}$, Gleason and PSA, according to the criterion proposed by the European Associaton of Urology [8], and established four groups: low risk (T1-T2a and Gleason $<7$ and PSA $<10$ ), medium (T2b or Gleason=7 or PSA between 10 and 20), high (T2c or Gleason $>7$ or PSA $>20$ ) and very high (T3-T4 or any $\mathrm{T}$ if $\mathrm{N}=1$ ).

Histology was categorized as: adenocarcinoma (8140), including acinar (8550); without histology (8000); and others $(8001,8010,8020,8041,8045,8246)$. 
We calculated the Charlson comorbidity index and grouped the cases in four categories: $0,1,2$ and $\geq 3$. Treatments were grouped in: local (prostatectomy, radiotherapy and cryosurgery); systemic (hormonal therapy or chemotherapy); mixed (combination of local and systemic); and observation/unknown (active surveillance, expectant attitude and unknown).

Statistical analysis: Multiple imputation (MI) was used to obtain stage when this was unknown, following three main steps [15]. First, we ran the imputation model and replaced each missing value with sets of 5, 10, 15 and 20 imputations by applying the multiple imputation chained equation (MICE) procedure. We assumed that the data were missing at random type. A more detailed description can be found in a previous manuscript [16]. Secondly, we analysed the resulting imputed and complete data sets independently by applying a Cox regression model. Finally, we applied a single Cox model using Rubin's rules [17] from each set of 5, 10, 15 and 20 estimates resulting from the previous Cox regression model. We selected the MI with 10 imputations because the increase to 15 or 20 changed neither the coefficient values nor the standard errors nor the degrees of significance.

Prior performing the survival analysis, the relationships between the variables were explored using contingency tables on which the Chi-square independence test [18] and the Cramer's V association index [19] were calculated.

As we knew the cause of death, we used CSS, but we also calculated the RS (relative survival) by the Ederer II method [20] using lifetables obtained from published official mortality data of Balearic Islands [14]. Due to the fact that the main survival studies such as EUROCARE and CONCORD have used RS, we decided to calculate both survivals in order to be able to compare them with each other and with the aforementioned studies.

We applied the survival analysis by the actuarial and Kaplan-Meier methods to estimate the likelihood of survival and risk of death; the log-rank test to evaluate the statistical differences of the observed survival curves by each categorical variable; and the Cox regression models to identify the prognostic factors associated with mortality risk. Age, histology, risk of progression, Charlson index and treatment were included in the Cox model, while stage, PSA and Gleason were excluded because they are part of the variable 
"risk of progression". Cases with low risk of progression were also excluded because their survival rate was $100 \%$. The proportional hazard assumption for each covariate was tested by introducing time-dependent variables.

Since risk and treatment did not meet this assumption, we applied the extended Cox regression model [21], which not only analyses the effect of covariates on the risk of dying but also allows for the modelling of the time-dependent effect of risk and treatment covariates. In this way, if the value of the hazard ratio associated to the time-dependent variable is higher than 1 , it means that the effect of the corresponding covariate on the risk of dying increases with time. On the contrary, if the value is lower than 1 , it means that the effect decreases with time.

The procedure for selecting the covariates in the final Cox model was based on the likelihood ratio (LR) test. To compare the effect of the imputation procedure on the hazard ratio estimation of covariates, the extended Cox regression model was performed both before and after MI.

MI was carried out with STATA 14, and survival analysis with SPSS (Statistical Package for the Social Sciences) 20.

\section{Results}

In total, 2921 cases of invasive prostate cancer were identified between 2006 and 2011. Stage was unknown in $53.9 \%$ of cases, while risk of progression was unknown in $24.5 \%$. After $\mathrm{MI}$, the distribution of cases by risk of progression was: $9.5 \%$ had low risk; $24.9 \%$ medium risk; $42.7 \%$ high risk and $22.9 \%$ very high risk. Full description of the sample is shown in Table 1.

Table 1. Clinical description of prostate cancer cases diagnosed in Mallorca between 2006-2011 (N = 2921).

\begin{tabular}{|c|c|c|c|c|c|}
\hline Variable & Categories & Number & $\%$ & $\%$ valid & After MI \\
\hline \multirow[t]{5}{*}{ Age } & $15-54$ & 163 & 5.6 & 5.6 & \\
\hline & $55-64$ & 817 & 28.0 & 28.0 & \\
\hline & $65-74$ & 1221 & 41.8 & 41.8 & \\
\hline & $75-84$ & 598 & 20.5 & 20.5 & \\
\hline & 85 or + & 122 & 4.2 & 4.2 & \\
\hline \multirow[t]{2}{*}{ Histology } & Adenocarcinoma & 2710 & 92.8 & 92.8 & \\
\hline & Unspecified & 161 & 5.5 & 5.5 & \\
\hline
\end{tabular}




\begin{tabular}{|c|c|c|c|c|c|}
\hline & Other & 50 & 1.7 & 1.7 & \\
\hline \multirow[t]{5}{*}{ T_PT } & 1 & 599 & 20.5 & 34.5 & \\
\hline & 2 & 756 & 25.9 & 43.5 & \\
\hline & 3 & 355 & 12.2 & 20.4 & \\
\hline & 4 & 27 & 0.9 & 1.6 & \\
\hline & Missing & 1184 & 40.5 & & \\
\hline \multirow[t]{3}{*}{ N_PN } & 0 & 1214 & 41.6 & 95.2 & \\
\hline & 1 & 61 & 2.1 & 4.8 & \\
\hline & Missing & 1646 & 56.4 & & \\
\hline \multirow[t]{3}{*}{ M } & 0 & 1908 & 65.3 & 90.9 & \\
\hline & 1 & 190 & 6.5 & 9.1 & \\
\hline & Missing & 823 & 28.2 & & \\
\hline \multirow[t]{5}{*}{ Stage } & 1 & 454 & 15.5 & 33.7 & \\
\hline & II & 438 & 15.0 & 32.5 & \\
\hline & III & 216 & 7.4 & 16.0 & \\
\hline & IV & 240 & 8.2 & 17.8 & \\
\hline & Missing & 1573 & 53.9 & & \\
\hline \multirow[t]{4}{*}{ PSA } & $\leq 10$ & 1025 & 35.1 & 59.4 & \\
\hline & $11-20$ & 306 & 10.5 & 17.7 & \\
\hline & $>20$ & 395 & 13.5 & 22.9 & \\
\hline & Missing & 1195 & 40.9 & & \\
\hline \multirow[t]{9}{*}{ Gleason } & 4 & 34 & 1.2 & 1.5 & \\
\hline & 5 & 134 & 4.6 & 5.8 & \\
\hline & 6 & 937 & 32.1 & 40.5 & \\
\hline & $7(3+4)$ & 615 & 21.1 & 26.6 & \\
\hline & $7(4+3)$ & 273 & 9.3 & 11.8 & \\
\hline & 8 & 166 & 5.7 & 7.2 & \\
\hline & 9 & 143 & 4.9 & 6.2 & \\
\hline & 10 & 13 & 0.4 & 0.6 & \\
\hline & Missing & 606 & 20.7 & & \\
\hline \multirow[t]{5}{*}{ Risk of progression } & Low & 189 & 6.5 & 8.6 & 9.5 \\
\hline & Medium & 512 & 17.5 & 23.2 & 24.9 \\
\hline & High & 971 & 33.2 & 44.0 & 42.7 \\
\hline & Very high & 533 & 18.2 & 24.2 & 22.9 \\
\hline & Missing & 716 & 24.5 & & \\
\hline \multirow[t]{4}{*}{ Charlson index } & 0 & 1745 & 59.7 & 59.7 & \\
\hline & 1 & 694 & 23.8 & 23.8 & \\
\hline & 2 & 295 & 10.1 & 10.1 & \\
\hline & $\geq 3$ & 187 & 6.4 & 6.4 & \\
\hline \multirow[t]{4}{*}{ Treatment } & Local & 1478 & 50.6 & 50.6 & \\
\hline & Systemic & 642 & 22.0 & 22.0 & \\
\hline & Mixed & 231 & 7.9 & 7.9 & \\
\hline & Observation/unspecified & 570 & 19.5 & 19.5 & \\
\hline \multirow[t]{4}{*}{ Vital status } & Alive & 2244 & 76.8 & 76.8 & \\
\hline & $\begin{array}{l}\text { Death from prostate } \\
\text { cancer }\end{array}$ & 324 & 11.1 & 11.1 & \\
\hline & Death from other causes & 349 & 12.0 & 12.0 & \\
\hline & Missing & 4 & 0.1 & & \\
\hline
\end{tabular}

Survival analysis was performed with 2917 cases because vital status was unknown for 4 cases. At the end of the study, a total of 2244 (76.8\%) patients had survived, 324 (11.1\%) died of prostate cancer, and 349 (12\%) died from other causes. Average time of survival was 2954 days (CI 95\% 2920-2987), with a standard error of 17.19. 
Table 2 presents the relationship of the treatment variable with the variables whose relationship has been more relevant. Treatment showed a more relevant relationship with age and life expectancy than with risk of progression and Charlson index and histology.

Table 2. Relationship of treatment with other variables.

\begin{tabular}{lccccc}
\hline & $\begin{array}{c}\text { Risk of } \\
\text { progression }\end{array}$ & $\begin{array}{c}\text { Charlson } \\
\text { index }\end{array}$ & Age & $\begin{array}{c}\text { Life } \\
\text { expectancy }\end{array}$ & Histology \\
\hline Cramer's V index $(p<.001)$ & .144 & .090 & .321 & .510 & .206 \\
Pearson's Chi-Square $(p<.001)$ & 137.75 & 71.63 & 902.44 & 759.99 & 248.48 \\
\hline
\end{tabular}

Table 3 shows no changes in CSS rates by year after MI for the whole sample. However, survival percentages by risk of progression were slightly higher after $\mathrm{MI}$, especially in very high risk cases; thus, without $\mathrm{MI}$, survival by risk and year would have been a little underestimated. At 5 years after diagnosis, survival after MI was $89 \%$ for the total of the sample: $100 \%$ for low risk cases, $96 \%$ for medium risk cases, $93 \%$ for high risk cases and $69 \%$ for very high risk cases.

Table 3. Cause-specific survival function by years of follow-up and risk of progression through actuarial method, before and after multiple imputation $(\mathrm{m}=10)$.

\begin{tabular}{cccccccccccc}
\hline & \multicolumn{4}{c}{$\begin{array}{c}\text { Original set } \\
\mathrm{n}=2202\end{array}$} & \multicolumn{3}{c}{$\begin{array}{c}\text { Imputed set } \\
\mathrm{n}=2917\end{array}$} \\
\hline Year & $\begin{array}{c}\text { Low } \\
\text { risk }\end{array}$ & $\begin{array}{c}\text { Medium } \\
\text { risk }\end{array}$ & $\begin{array}{c}\text { High } \\
\text { risk }\end{array}$ & $\begin{array}{c}\text { Very } \\
\text { high risk }\end{array}$ & Total & $\begin{array}{c}\text { Low } \\
\text { risk }\end{array}$ & $\begin{array}{c}\text { Medium } \\
\text { risk }\end{array}$ & $\begin{array}{c}\text { High } \\
\text { risk }\end{array}$ & $\begin{array}{c}\text { Very } \\
\text { high risk }\end{array}$ & Total \\
\hline 1 & 1.00 & .99 & .99 & .86 & .96 & 1.00 & .99 & .98 & .86 & .96 \\
2 & 1.00 & .98 & .97 & .77 & .93 & 1.00 & .98 & .96 & .79 & .93 \\
3 & 1.00 & .97 & .94 & .72 & .91 & 1.00 & .97 & .94 & .74 & .91 \\
4 & 1.00 & .97 & .93 & .70 & .90 & 1.00 & .97 & .93 & .72 & .90 \\
5 & 1.00 & .95 & .92 & .67 & .89 & 1.00 & .96 & .93 & .69 & .89 \\
6 & 1.00 & .95 & .90 & .65 & .88 & 1.00 & .96 & .91 & .67 & .88 \\
7 & 1.00 & .94 & .88 & .65 & .87 & 1.00 & .95 & .89 & .67 & .87 \\
8 & 1.00 & .92 & .87 & .65 & .86 & 1.00 & .93 & .88 & .67 & .86 \\
9 & 1.00 & .87 & .87 & .62 & .84 & 1.00 & .91 & .88 & .64 & .84 \\
\hline
\end{tabular}

Table 4 displays 5RS by risk of progression before and after MI. As CSS, RS doesn't show changes for total cases between before and after MI with a value of $91 \%$. Slightly higher survival rates were also observed in very high risk cases after MI. 
Table 4. 5-year relative survival by risk of progression before and after multiple imputation.

\begin{tabular}{lcc}
\hline & $\begin{array}{c}\text { Original set } \\
\mathrm{n}=2202\end{array}$ & $\begin{array}{c}\text { Imputed set } \\
\mathrm{n}=2917\end{array}$ \\
\hline Total & 0.91 & 0.91 \\
Low risk & 1.00 & 1.00 \\
Medium risk & 0.99 & 0.98 \\
High risk & 0.94 & 0.94 \\
Very high risk & 0.68 & 0.70 \\
\hline
\end{tabular}

Survival curves showed differences $(p<.001)$ by age, risk of progression, histology, PSA, Gleason score and treatment (Figure 1). Prostate cancer survival diminishes markedly in people over 75 years old, with very high risk of progression, histology other than adenocarcinoma, PSA values at diagnosis $>20$, Gleason values $\geq 8$, or after a systemic treatment. However, there is not a clear relationship between Charlson index and survival.

Figure 1. Survival curves of prostate cancer cases diagnosed in Mallorca between 2006-2011 by (a) age, (b) risk, (c) histology, (d) PSA, (e) Gleason, (f) treatment and (g) Charlson score.

The LR test included Charlson index, risk of progression, histology, treatment and time-dependent variables (risk of progression and treatment) in the final Cox model. Age was excluded, because of the detected relationship between age and treatment. Table 5 shows the results of the Cox model before and after MI. Both models (original vs MI model) determined that patients with a Charlson index of 2 or more have worse prognosis than those with an index of 0 ; however, those with an index of 3 do not have a worse prognosis than those with an index of 2 after MI. Also, patients with histology other than adenocarcinoma; with high risk of progression and, especially, very high risk; and with systemic, mixed and observation/unspecified treatments have worse prognosis as well. Time-dependent variables show that the effect of systemic treatment instead of local treatment over risk of dying increases over time after MI. In general, standard errors were lower after MI, showing us a better adjusted model.

Table 5. Cox regression model of prostate cancer diagnosed in Mallorca between 2006 and 2011 before and after multiple imputation $(m=10)$. 


\begin{tabular}{|c|c|c|c|c|c|c|c|c|}
\hline & \multicolumn{4}{|c|}{$\begin{array}{c}\text { Model } 1 \\
\text { (Original data set) } \\
\mathrm{n}=2013\end{array}$} & \multicolumn{4}{|c|}{$\begin{array}{c}\text { Model } 2 \\
\text { (Imputed data set) } \\
\mathrm{n}=2728\end{array}$} \\
\hline & $\begin{array}{c}\text { Hazard } \\
\text { ratio }\end{array}$ & $\begin{array}{l}\text { Std. } \\
\text { Err. }\end{array}$ & $p$ & $95 \% \mathrm{Cl}$ & $\begin{array}{c}\text { Hazard } \\
\text { ratio }\end{array}$ & $\begin{array}{l}\text { Std. } \\
\text { Err. }\end{array}$ & $p$ & $95 \% \mathrm{Cl}$ \\
\hline \multicolumn{9}{|l|}{ Main variables } \\
\hline \multicolumn{9}{|l|}{ Charlson index (ref. 0) } \\
\hline Charlson = 1 & 0.86 & 0.13 & 0.309 & $0.63 ; 1.15$ & 0.89 & 0.13 & 0.427 & $0.66 ; 1.19$ \\
\hline Charlson = 2 & 2.08 & 0.37 & 0.000 & $1.46 ; 2.96$ & 1.76 & 0.29 & 0.001 & $1.26 ; 2.44$ \\
\hline Charlson $>=3$ & 1.61 & 0.36 & 0.035 & $1.03 ; 2.50$ & 1.10 & 0.25 & 0.674 & $0.70 ; 1.73$ \\
\hline \multicolumn{9}{|c|}{ Risk of progression (ref. medium) } \\
\hline High risk & 2.82 & 1.16 & 0.012 & $1.26 ; 6.32$ & 2.82 & 1.19 & 0.017 & $1.21 ; 6.57$ \\
\hline Very high risk & 9.85 & 4.06 & 0.000 & $4.38 ; 22.11$ & 14.08 & 5.22 & 0.000 & $6.76 ; 29.35$ \\
\hline \multicolumn{9}{|l|}{ Histology (ref. adenoc.) } \\
\hline Unspecified & 4.01 & 0.60 & 0.000 & $2.98 ; 5.39$ & 5.69 & 0.81 & 0.000 & $4.29 ; 7.54$ \\
\hline Others & 3.86 & 1.35 & 0.000 & $1.94 ; 7.67$ & 2.63 & 1.00 & 0.013 & $1.23 ; 5.61$ \\
\hline \multicolumn{9}{|l|}{ Treatment (ref. local) } \\
\hline Systemic & 67.82 & 34.61 & 0.000 & $24.94 ; 184.41$ & 68.07 & 30.70 & 0.000 & $28.12 ; 164.79$ \\
\hline Mixed & 8.74 & 5.38 & 0.000 & $2.61 ; 29.22$ & 12.03 & 6.66 & 0.000 & $4.06 ; 35.62$ \\
\hline Observation/unspecified & 40.94 & 22.69 & 0.000 & $13.82 ; 121.32$ & 19.07 & 9.21 & 0.000 & $7.40 ; 49.15$ \\
\hline \multicolumn{9}{|c|}{ Time-dependent variables } \\
\hline \multicolumn{9}{|c|}{ Risk of progression (ref. Medium) } \\
\hline High risk & 0.98 & 0.25 & 0.949 & $0.59 ; 1.63$ & 0.97 & 0.23 & 0.898 & $0.59 ; 1.60$ \\
\hline Very high risk & 0.72 & 0.17 & 0.172 & $0.44 ; 1.15$ & 0.94 & 0.20 & 0.789 & $0.61 ; 1.46$ \\
\hline \multicolumn{9}{|l|}{ Treatment (ref. local) } \\
\hline Systemic & 1.43 & 0.38 & 0.171 & $0.86 ; 2.40$ & 1.56 & 0.31 & 0.025 & $1.06 ; 2.29$ \\
\hline Mixed & 0.91 & 0.27 & 0.761 & $0.51 ; 1.64$ & 1.09 & 0.26 & 0.707 & $0.68 ; 1.76$ \\
\hline Observation/unspecified & 0.89 & 0.24 & 0.670 & $0.53 ; 1.50$ & 0.81 & 0.15 & 0.281 & $0.56 ; 1.18$ \\
\hline
\end{tabular}

\section{Discussion}

Prostate cancer 5RS in Mallorca achieved 91\% for the patients diagnosed in the period 2006-2011 which is close to the 5-year age-standardized RS found by CONCORD-3 study for 10 Spanish registries for the period 2005-2009 (90.4\%) [22] and slightly higher than the 5RS found by EUROCARE-5 study for Spain for the period 2000-2007 (84.6\%) and the 5-year age-standardized RS for Europe for the period 2000-2007 (83.4\%) [3].

On the other hand, the CSS (89\%) was two percentage points lower than the 5RS. CSS and RS are widely used in medical research but neither methodology achieves a perfect net survival estimate and therefore the strengths and limitations of both methodologies must be known. The main limitation of CSS may be the errors resulting from the misclassification of the cause of death, while the main limitation of RS may be the unavailability of adequate life tables, especially in cancers in which regular screening is performed or in cancers with risk factors also associated with other causes of death such as tobacco.

In studies comparing SR and CSS, most cancers show a higher CSS than SR with the exception of cancers detectable by screening. Prostate cancer shows the greatest difference in all this type of studies $[23,24,25]$. 
In the most recent study on this topic, which included more than 700,000 prostate cancer cases from 18 SEER (Surveillance, Epidemiology, and End Results) Program registries, the RS was 4.8 percentage points higher than the CSS. In a study by Makkan et al, the difference was 5.7 percentage points. However, the difference between RS and CSS in Mallorca was only of 2 percentage points and this could indicate high quality of our data on cause of death due to a meticulous review carried out of the medical histories.

Risk of progression and treatment were the main factors associated to survival, but the histology and Charlson index were also independent prognostic factors. Age was not associated to survival after adjusting by treatment.

We chose risk of progression instead of stage because the percentage of missing values in stage was too high (>50\%). We could have assigned $\mathrm{N}$ or $\mathrm{M}$ values to stage [26], but the low percentage of missing values in risk of progression made possible the use of $\mathrm{MI}$, which many authors recommend and use in prostate cancer [27] and other types of cancer [16, 28-31].

We observed that risk of progression was a strong predictor of survival. While survival in low risk cases was $100 \%$, very high risk cases presented a survival 14 times worse than medium risk cases. The identification of these high risk cases at diagnosis is crucial, especially because treatment is also a strong predictor of survival. So, high risk prostate cancer cases warrant treatment with an integrated approach including surgery, radiotherapy and systemic therapy [32].

Surprisingly, the choice of treatment depended mostly on age, not on risk or even on comorbidity. A similar result was observed by some authors [33], but others showed that in subsequent periods, this association between treatment and age could change [34]. When we included the treatment variable, age fell out of the model and then the model fitted better. Thus, our results could question the independent effect of age on prostate cancer survival obtained in other studies [35].

Comorbidity increases the risk of dying from other causes in prostate cancer but, as we have shown in our study, the effects of comorbidity on prostate cancer CSS are not clear, because survival worsens in cases with Charlson index of 2 but not in cases with Charlson index of 3 or above. The independent effect of comorbidity was found in other studies, some of them population-based $[35,36]$. The largest population-based study 
restrained to a specific stage [36] in the United States, shows that a higher comorbidity score is, in general, associated with higher overall mortality and lower prostate cancer-specific mortality.

Based on European Association of Urology, during the period of time in which the patients in this study were treated, that is, from 2006 to 2011, the treatment recommendations were based on the stage and secondarily on the PSA that transferred to current guidelines would be the risk of progression. However, in our study, we have seen that treatment has been more related to age and life expectancy, and therefore, we interpret that the follow-up of the recommendations would not have been desirable as has already been seen in other studies [37] and in a previous study of ours [38].

The strength of this study is that the sample was population-based and it included all categories of risk. We were able to follow some of the cases up to nine years. Moreover, we knew the cause of death, which allowed us to calculate cause-specific survival.

The limitations of the study are related to the fact that the information came only from one cancer registry, so the external validity could be questioned. In addition, it would be desirable to have more recent data.

In summary, the risk of progression and treatment, and not age, were the main variables associated with survival in prostate cancer. The association between comorbidity and survival in prostate cancer is not clear.

\section{Conclusions}

Cancer prostate has very good 5 years survival. Nevertheless, it drops from of $91 \%$ to $69 \%$ in very high risk of progression cases, which represent nearly one of four prostate cancers. So, their identification should be a priority.

Treatment is an independent prognostic factor in prostate cancer, and it is associated with age and life expectancy, not with risk of progression or histology, also independent prognostic factors. Instead, age and comorbidity are not clear prognostic factors in prostate cancer.

\section{List of abbreviations}

PSA: Prostate-specific antigen 
ICD-O: International Classification of Diseases for Oncology

MI: Multiple imputation

ASIRw: world age-standardized incidence rate

REDECAN: Spanish Network of Cancer Registries

5RS: 5-year relative survival

UICC: International Union Against Cancer

CSS: Cause-specific survival

DCO: Death certificate only

MICE: Multiple imputation chained equation

RS: Relative survival

LR: Likelihood ratio

SPSS: Statistical Package for the Social Sciences

SEER: Surveillance, Epidemiology, and End Results

\section{DECLARATIONS}

\section{Ethics approval and consent to participate}

The human sujects in our project have participated willingly, having been adequately informed about the research. This study was approved by the ethics committee of Balearic Islands on the 23rd July 2014. (IB 2363/14).

\section{Consent for publication}

Our manuscript doesn't contain any individual person's data in any form. All authors have approved the submitted manuscript.

\section{Availability of data and material}

The dataset used and analysed during the current study are available from the corresponding author on reasonable request.

\section{Competing interests}

We declare that we have no competing interests. 


\section{Funding}

This study was funded (design of the study and collection, analysis, and interpretation of data) by a public grant from the Ministry of Health, Carlos III Institute and the European Union (FEDER) (PI14/01199).

\section{Authors' contributions}

JJ Montaño: Data analysis and interpretation of results.

A Barceló: Data collection and drafted of the manuscript.

P Franch: Data collection and interpretation of results.

J Galceran: Global review of the work.

A Ameijide: Data analysis.

J Pons: Interpretation of data and results.

M Ramos: Conception, design and review of the work.

\section{Acknowledgements}

We are deeply grateful to Juan Gervasio Rebollo Roca for his English review of the manuscript.

\section{References}

1. Cancer today. Global Cancer Observatory. International Agency for Research on Cancer. Available at: http://gco.iarc.fr/today/home [accessed the 10/10/19].

2. Estimaciones de la incidencia del cáncer en España, 2020. Red Española de Registros de Cáncer (REDECAN), 2020. Available at: https://redecan.org/redecan.org/es/estimacionesincidencia2020.html?id=196\&title=estimaciones-de-la-incidencia-del-c\%C3\%A1ncer-enEspa\%C3\%B1a-2020 [accessed the 03/01/2021].

3. Trama A, Foschi R, Larrañaga N, et al. Survival of male genital cancers (prostate, testis and penis) in Europe 1999-2007: Results from the EUROCARE-5 study. Eur J Cancer. 2015;51:2206-2216.

4. Marcos-Gragera R, Salmerón D, Izarzugaza I, et al. Trends in prostate cancer-survival in Spain: results from population-based cancer registries. Clin TransI Oncol. 2012;14:458-64. 
5. Allemani C, Weir HK, Carreira H, et al. Global surveillance of cancer survival 1995-2009: analysis of individual data for 25676887 patients from 279 population-based registries in 67 countries (CONCORD-2). Lancet 2015;385:977-101.

6. Sobin LH, Gospodarowicz MK, Wittekind C. TNM Classification of malignant tumours. 7 th ed. UICC. Oxford: Wiley-Blackwell; 2011.

7. Rodrigues G, Warde P, Pickles $T$, et al. Pre-treatment risk stratification of prostate cancer patients: A critical review. Can Urol Assoc J. 2012;6(2):121-7.

8. Mottet N, Cornford P, van den Bergh RCN, et al. Prostate Cancer. European Association of Urology. Available at: https://uroweb.org/guideline/prostate-cancer/\#6_6 [accessed the 08/03/21].

9. Patel KM, Gnanapragasam VJ. Novel concepts for risk stratification in prostate cancer. J Clin Urol. $2017 ; 9(2 S): 18-23$

10. Klein EA. Prostate cancer: Risk stratification and choice of initial treatment. UpToDate; 2018. Available at: https://www.uptodate.com/contents/prostate-cancer-risk-stratification-and-choiceof-initial-treatment [accessed the 15/10/19].

11. Houterman S, Janssen-Heijnen J, Hendrikx AJM, et al. Impact of comorbidity on treatment and prognosis of prostate cancer patients: A population-based study. Crit Rev Oncol Hematol. 2006;58:60-7.

12. Matthes KL, Limam M, Dehler S, et al. Primary treatment choice over time and relative survival of prostate cancer patients: Influence of age, grade and stage. Oncol Res Treat. 2017; 40:484-9.

13. Fritz A, Percy C, Jack A, et al. International classification of diseases for oncology (ICD-O), 1st rev., 3rd ed. Geneva: World Health Organization; 2013. Available at: https://apps.who.int/iris/bitstream/handle/10665/96612/9789241548496\%20eng.pdf;jsessionid=7 B2E052FBC84832B13B32AC8B483E069?sequence=1 [accessed the 15/10/19].

14. Statistics. Populations. Deaths. Institut Balear d'Estadística. Available at: https://ibestat.caib.es/ibestat/estadistiques/poblacio/defuncions/c15a61f7-b12e-42d7-abedbb6f03343656 [checked the 15/10/19]. 
15. White IR, Royston P, Wood AM. Multiple imputation using chained equations: issues and guidance for practice. Statist Med. 2011;30:377-399.

16. Ramos M, Montaño JJ, Esteva M, et al. Colorectal cancer survival by stage of cases diagnosed in Mallorca, Spain, between 2006 and 2011 and factors associated with survival. Cancer Epidemiol. 2016;41:63-70.

17. Rubin DB. Multiple imputation for nonresponse in surveys. New York: John Wiley \& Sons; 1987.

18. Pearson K. On the theory of contingency and its relation to association and normal correlation. Drapers Company Memoirs, Biometric Series 1. 1904.

19. Cramer H. Mathematical models of statistics. Princeton: Princeton University Press. 1946.

20. Ederer F, Axtell IM, Cutler SJ. The relative survival: a statistical methodology. Natl Cancer Inst Monog. $1961 ; 6: 101-121$.

21. Blossfeld HP, Rohwer G. Techniques of event history modeling: New approaches to causal analysis. Hillsdale, NJ, US: Lawrence Erlbaum Associates; 1995.

22. Allemani C, Matsuda T, Di Carlo V, et al. Global surveillance of trends in cancer survival 2000-14 (CONCORD-3): analysis of individual records for 37513025 patients diagnosed with one of 18 cancers from 322 population-based registries in 71 countries. Lancet. 2018;391(10125):1023-1075.

23. Forjaz de Lacerda G, Howlader N, Mariotto AB. Differences in cancer survival with relative versus cause-specific approaches: an update using major accurate life tables. Cancer Epidemiol Biomakers Prev. 2019;28(9):1544-1551.

24. Makkar N, Ostrom Q, Kruchko C, Barnholtz-Sloan J. A comparison of relative survival and causespecific survival methods to measure net survival in cancer populations. Cancer Med. 2018; $7(9): 4773-4780$.

25. Skyrud KD, Bray F, Møller B. A comparison of relative and cause-specific survival by cancer site, age and time since diagnosis. Int J Cancer. 2014;135:196-203.

26. Parry MG, Sujenthiran A, Cowling TE, et al. Imputation of missing prostate cancer stage in English cancer registry data based on clinical assumptions. Cancer Epidemiol. 2019; 58:44-51. 
27. Luo Q, Egger $S$, Yu XQ, et al. Validity of using multiple imputation for "unk-nown" stage at diagnosis in population-based cancer registry data. PloS One.2017;12:e0180033.

28. Hoskin TL, Boughey JC, Day CN, et al. Lessons learned regarding missing clinicalstage in the national cancer database. Ann Surg Oncol. 2019;26:739-45.30.

29. Ramos M, Montaño J, Rubio A, et al. Lung cancer survival by stage of cases diagnosed in Mallorca, Spain, between 2006 and 2011 and factors associated with survival. Pulm Med Respir Res. 2017;3:16.

30. Eisemann N, Waldmann A, Katalinic A. Imputation of missing values of tumour stage in populationbased cancer registration. BMC Med Res Methodol.2011;11:129.

31. Clark TG, Altman DG. Developing a prognostic model in the presence of missing data: an ovarian cancer case study. J Clin Epidemiol. 2003;56:28-37.

32. Alvarez-Maestro M, Quesada J, Gómez J, et al. High-risk prostate cancer. Optimal treatment. New evidences. Arch Esp Urol. 2019; 72(2):203-10.

33. Matthes KL, Limam M, Pestoni G, et al. Impact of comorbidities at diagnosis on prostate cancer treatment and survival. J Cancer Res Clin Oncol. 2018;144(4):707-15.

34. Matthes KL, Liman M, Dehler S, et al. Primary treatment choice over time and relative survival of prostate cancer patients: Influence of age, grade and stage. Oncol Res Treat. 2017;40:484-9.

35. Houterman S, Janssen-Heijnen MLG, Hendrikx AJM, et al. Impact of comorbidity on treatment and prognosis of prostate cancer patients: A population-based study. Crit Rev Oncol Hematol. 2006;58(1):60-7.

36. Albertsen PC, Moore DF, Shih W, et al. Impact of comorbidity on survival among men with localized prostate cancer. J Clin Oncol. 2011;29(10):1335-41.

37. Heins M, de Jong J, Spronk I, et al. Adherence to cancer treatment guidelines: influence of general and cancer-specific guideline characteristics. Eur J Public Health. 2016;27(4):616-620.

38. Barceló A, Ramos M, de la Iglesia M, Zaforteza, M. Tratamiento del cáncer de próstata en función de la esperanza de vida, la comorbilidad y las guías de práctica clínica. An Sist Sanit Navar. 2014;37(3):309-460. 


\section{Figure legends}

\section{Figure 1:}

a. Survival by Age

Follow-up in years

Age $=15-54$

Age $=55-64$

Age $=65-74$

Age $=75-84$

Age $=85$ or more

b. Survival by Risk of progression

Follow-up in years

Risk=Low

Risk=Medium

Risk=High

Risk=Very high

c. Survival by Histology

Follow-up in years

Histology=Adenocarcinoma

Histology=Unespecified

Histology $=$ Others

d. Survival by PSA

Follow-up in years

PSA=Less or equal to 10 
PSA=Between 11 and 20

PSA=More than 20

e. Survival by Gleason

Follow-up in years

Gleason=4

Gleason=5

Gleason=6

Gleason=7(3+4)

Gleason=7(4+3)

Gleason=8

Gleason=9

Gleason=10

f. Survival by Treatment

Follow-up in years

Treatment=Local

Treatment=Systemic

Treatment=Mixed

Treatment=Obser./Unespec.

g. Survival by Charlson score

Follow-up in years

Charlson $=0$

Charlson=1

Charlson=2

Charlson=3 or more 
Figures
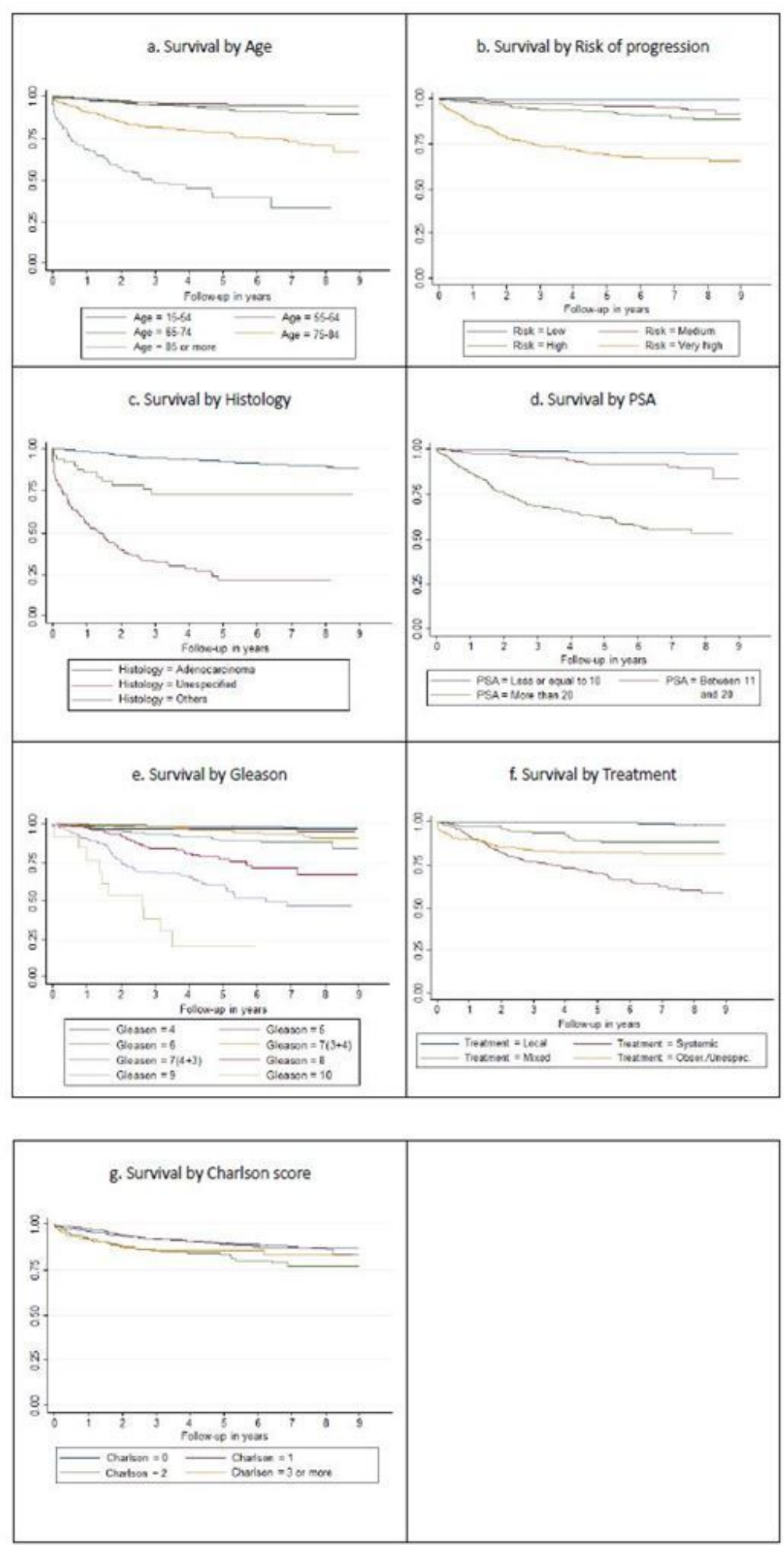

\section{Figure 1}

a. Survival by Age Follow-up in years Age=15-54 Age=55-64 Age=65-74 Age=75-84 Age=85 or more b. Survival by Risk of progression Follow-up in years Risk=Low Risk=Medium Risk=High Risk=Very high c. Survival by Histology Follow-up in years Histology=Adenocarcinoma Histology=Unespecified 
Histology=0thers $\mathrm{d}$. Survival by PSA Follow-up in years PSA=Less or equal to 1019 PSA=Between 11 and 20 PSA=More than 20 e. Survival by Gleason Follow-up in years Gleason=4 Gleason $=5$ Gleason $=6$ Gleason=7(3+4) Gleason=7(4+3) Gleason=8 Gleason=9 Gleason=10 f. Survival by Treatment Follow-up in years Treatment=Local Treatment=Systemic Treatment=Mixed Treatment=Obser./Unespec. g. Survival by Charlson score Follow-up in years Charlson $=0$ Charlson $=1$ Charlson $=2$ Charlson $=3$ or more 